\title{
Water-saving traits can protect wheat grain number under progressive soil drying at the meiotic stage: a phenotyping approach
}

\author{
by Faralli, M., Williams, K.S., Han, J., Corke, F.M., \\ Doonan, J.H. and Kettlewell, P.S.
}

Copyright, Publisher and Additional Information: This is the authors' accepted manuscript. The final published version (version of record) is available online via SpringerLink

Please refer to any applicable terms of use of the publisher.

DOI: https://doi.org/10.1007/s00344-019-09956-3 
1 Water-saving traits can protect wheat grain number under progressive soil drying at

2 the meiotic stage: a phenotyping approach

3 Michele Faralli ${ }^{12 * \dagger}$, Kevin S. Williams ${ }^{2 *}$, Jiwan Han ${ }^{2}$, Fiona M.K. Corke ${ }^{2}$, John H. Doonan ${ }^{2}$, $4 \quad$ Peter S. Kettlewell ${ }^{1}$

$5{ }^{1}$ Department of Crop and Environment Sciences, Harper Adams University, Newport, 6 Shropshire, TF10 8NB, UK.

$7 \quad{ }^{2}$ National Plant Phenomics Centre, Aberystwyth University, Aberystwyth, SY23 3EB, UK.

$8 \quad$ * Corresponding authors email: m.faralli@essex.ac.uk; ksw09@aber.ac.uk

$9 \dagger$ Present address: School of Biological Sciences, University of Essex, Wivenhoe Park, 10 Colchester, CO4 3SQ, UK

11 Keywords: Triticum aestivum L., conservative and non-conservative water use, water-use efficiency, shoot phenotyping, seed set, antitranspirant, stomatal conductance

Running title: Water-saving strategies at wheat meiosis 


\section{Abstract}

In wheat, water deficit during meiosis of pollen mother cells greatly reduces seed set and grain number. A promising option to avoid grain losses and maintain wheat productivity under water stress is to exploit conservative water-use strategies during reproduction. In this work two cultivars known to be adapted to different environments were studied. Water stress, with or without a polymer spray known to reduce stomatal conductance, was applied to both cultivars just prior to meiosis. Two experiments were carried out in a phenotyping platform to 1) assess and validate daily non-destructive estimation of projected leaf area and to 2) to evaluate different water-use (WU) strategies across the meiotic period and their effect on physiology and yield components.

Gladius displays an elevated breakpoint (BP) in the regression of WU against fraction of transpirable soil water (FTSW) for both daily and night-time WU suggesting higher conservative whole-plant response when compared to Paragon. At the same time, Gladius maintained flag leaf gas-exchange with a significant reduction at $\sim 0.2$ FTSW only, suggesting an uncoupled mechanism of WU reduction that optimized the water resource available for flag leaf gas-exchange maintenance. Under progressive soil drying, seed set and grain number of tillers stressed at GS41 were significantly reduced in Paragon $(\mathrm{P}<0.05)$ thus leading to lower grain yield and grain number reduction at plant level than Gladius. Polymer-induced reduction of transpiration is potentially useful when applied to the non-conservative stressed Paragon, maintaining higher FTSW, water-use efficiency and RWC during the progressive soil drying treatment. This lead to better seed set $(\mathrm{P}<0.05)$ and grain number maintenance $(\mathrm{P}<0.05)$ than in the stressed Paragon control.

We conclude that the different conservative traits detected in this work, protect grain development around meiosis and therefore maintain grain number under water limiting conditions. Additionally, non-conservative genotypes (often with a greater expected yield potential) can be protected at key stages by reducing their water use with a polymer spray. Thus, future efforts can integrate both crop breeding and management strategies to achieve drought-resilience during the early reproductive phase in wheat and potentially other cereals. 


\section{Introduction}

Grain yield reduction due to lack of water resources is a primary problem in many species of cereals. Grain number and grain weight (the primary yield-determining components in wheat) are affected by water stress, depending on the magnitude, duration and the phenological stage at which the stress occurs (Barnabás et al. 2008; Farooq et al. 2014). In particular, early reproductive phases are highly sensitive stages in wheat (Saini and Westgate 1999; Ji et al. 2010) and water stress leads to high yield losses mainly by decreasing the grain number following limited seed set (Ji et al. 2010; Onyemaobi et al. 2017). Pre-reproductive stage water stress (e.g. at tillering or during differentiation of the floral meristem) can reduce grain number due to reduction in total spike number and in spikelet number per spike ( $\mathrm{Ji}$ et al. 2010). However, seed set reduction following water stress later in development is primarily due to sensitivity in reproductive structures of the cleistogamous floret, and is particularly evident during meiosis in pollen mother cells (Saini 1997; Ji et al. 2010; Weerasinghe et al. 2016), commonly accepted to occur at Growth Stage 41 (GS41). Depending on the magnitude of stress and the growing conditions, reduction of soil water availability at meiotic stages reduces grain number or seed set from 30\% up to 50\% (Weerasinghe et al. 2016; Onyemaobi et al. 2017). Although recent work shows that genotypic variation is also present for sensitivity to water restriction of female organ development (Onyemaobi et al. 2017), there is longstanding evidence that several environmental stresses drastically affect the male gametophyte leading to pollen sterility (Bingham, 1966; Ji et al. 2011; Lalonde et al. 1997; Ji et al. 2010). One mechanism involves degradation of the tapetum, leading to damage at the anther layers and associated with reduction of starch accumulation of the pollen grains (Saini et al. 1984). Even moderate water stress (i.e. without a reduction in spikelet water potential) (Saini and Westgate, 1999) can induce pollen sterility, suggesting potential involvement of hormone-derived signals (e.g. abscisic acid, ABA) that modify sugar metabolism (Morgan 1980; Westgate et al. 1996; Oliver et al. 2007). Therefore, soil water conservation strategies are of primary importance during the meiotic stages for grain number determination and yield maintenance under reduced soil water availability.

Water-use strategies determine the efficacy of a crop to optimize water resource utilisation under disadvantageous environments. So-called non-conservative phenotypes are mostly advantageous when water resources are not scarce and yield potential can be achieved (Blum, 2009). Under more severe water stress conditions, rain-fed crops rely on stored soil water and, therefore, conservative phenotypes are preferable owing to their slower use of available water 
(Rizza et al. 2012; Tuberosa 2012; Nakhforoosh et al. 2016). For instance, there is evidence of a significant yield benefit when genotypes with early decrease in transpiration (i.e. when soil moisture is still significantly available) are grown under rain-fed conditions (Sinclair and Muchow 2001). This suggests that, during cyclic periods of water scarcity, this conservative behaviour can avoid the onset of water stress until the next rain event (Schoppach and Sadok 2012). Although genotypic variation has been already shown for the conservative strategies proposed above (Schoppach and Sadok 2012), there are few reports linking these strategies to critical growth stages when yield components, such as grain number, are determined. Both morphological and physiological factors can substantially contribute to the phenotypic response to water deficit and therefore affect grain yield production (Tuberosa 2012). For example, variation in water loss through stomata (physiological trait) combined with variation in the total leaf area devoted to transpiration (morphological trait) synergistically determine the balance between non-conservative and conservative phenotypes (Nakhforoosh et al. 2016). Responses of stomata to environmental cues (Lawson and Blatt 2014), stomatal sensitivity to drought-induced signals (Jia and Davies 2007), stomatal density (Hetherington and Woodward 2003) and stomatal pore length (Franks and Beerling, 2009) determine the rate of physiological regulation through stomatal conductance per unit of leaf area of the plant at a given environmental condition. Total leaf area (Nakhforoosh et al. 2016), canopy architecture (Wilson et al. 2005) and root traits (de Dorlodot et al. 2007) are morphological factors that contribute to total plant water loss.

Thus, a complex interplay between physiology, morphology, genetics and environment determines the whole-plant response to stress but the degree of damage that can occur at a yield-determining stage such as meiosis is critical. Understanding how soil moisture is depleted could avoid i) seed set reduction during the early reproductive phase and ii) maintain water availability during the grain filling stage and iii) avoiding the onset of the terminal stress. This approach could permit selection of genotypes with elevated resilience to water stress at critical stages and allow the mechanisms underlying the yield protection to be further exploited both in crop breeding and crop management.

Our hypothesis, therefore, is that water-saving strategies can sustain seed set and other yieldrelated traits in wheat subjected to reduced water availability during meiosis. To assess the effect of the total leaf area on water-use non-destructively, an experiment (Experiment 1) was carried out to validate a protocol for projected leaf area estimation through imaging. Subsequently (Experiment 2), we tested two cultivars both widely used as parental lines in mapping populations (Maphosa et al. 2014). Gladius is adapted to a climate with generally sub- 
optimal water supply (Maphosa et al. 2014) while Paragon (an elite UK spring wheat) is mainly adapted and grown under a relatively high rainfall region. The cultivars have contrasting total projected leaf area, a comparable rate of stomatal conductance at saturating light and flag leaf stomatal density but potentially different stomatal sensitivity to water stress. In addition, a polymer treatment well known to increase the leaf stomatal resistance to water vapour was used. This treatment was applied just prior to GS41 in order to evaluate the degree of efficiency of the water-saving induced strategy over meiosis at maintaining final seed set. Estimation of daily and night-time plant water use, non-destructive estimation of projected leaf area through imaging, physiological and yield measurements provided a morpho-physiological evaluation of the contrasting water-use behaviour in relation to reduced soil water availability across the meiotic stages.

\section{Materials and Methods}

\section{Experiment 1}

\section{Experimental setup}

Spring wheat grains (Triticum aestivum L., cv. Paragon) were germinated and grown in pots (3.5 L, 30 pots in total) that each contained $1100 \mathrm{~g}$ of growing substrate (Levington F2, Fisons, Suffolk, UK) on a conveyor system (Lemnatec GmbH, Pascalstraße 59. 52076 Aachen, Germany) at the National Plant Phenomics Centre (NPPC) greenhouse. Plants were automatically watered daily to a set target weight of $2350 \mathrm{~g}$. During the experiment, plants were grown at $\sim 18 / 15^{\circ} \mathrm{C}$ day/night temperature on average and $\sim 60 \%$ of relative humidity with an average daily photon flux density of $400 \mu \mathrm{mol}$ photons $\mathrm{m}^{-2} \mathrm{~s}^{-1}$ from natural light supplemented by high-pressure sodium lamps (14-hr/10-hr light-dark photoperiod) system.

\section{Calibration of projected leaf area against above ground fresh and dry weight.}

At GS12 (second leaf unfolded, BBCH wheat growth scale) (Lancashire et al. 1991) until GS69 (flowering completed), plants $(n=3)$ were analysed weekly. Initially, plants were imaged in the conveyor system from three sides with RGB cameras and then immediately the above ground biomass was harvested and weighed (fresh weight, g). Samples were then oven-dried at $80^{\circ} \mathrm{C}$ for $48 \mathrm{~h}$ and weighed again (dry weight, $\mathrm{g}$ ). The projected leaf area $\left(\mathrm{cm}^{2}\right)$ was estimated from the images as number of green pixels segmented from each image and scaled to a calibration standard. To assess the validity of the projected leaf area values, the data were then plotted (fresh and dry weight to image-estimated projected leaf area in $\mathrm{cm}^{2}$ ) (Supplementary Fig. 1) 


\section{Experiment 2}

\section{Experimental setup}

Spring wheat grain (Triticum aestivum L., cv. Paragon and Gladius) were sown on the $10^{\text {th }}$ October 2016 for Paragon and on the $17^{\text {th }}$ October 2016 for Gladius, as two grains per $3.5 \mathrm{~L}$ pot that all contained $1100 \mathrm{~g}$ of growing substrate (Levington F2, Fisons, Suffolk, UK). The one-week difference in sowing date was due to the different cultivar phenology as, from previous experiments in similar growing conditions, Gladius reached GS 41 (BBCH wheat growth scale) (Lancashire et al. 1991) one week earlier than Paragon. Grains were germinated in controlled environmental conditions at $\sim 200 \mu \mathrm{mol} \mathrm{m}^{-2} \mathrm{~s}^{-1}, 14$ hour day $18 / 15^{\circ} \mathrm{C}$ day/night temperature, with $\sim 60 \%$ relative humidity. The two cultivars were chosen as they show very different total shoot biomass and are adapted to contrasting environments (Paragon, high total biomass and UK-grown cultivar; Gladius, low-total biomass and Australian-grown cultivar) although their flag leaves had similar stomatal density under our growing conditions (Supplementary Fig. 2). One week after germination, seedlings were thinned to one per pot, selecting for those with uniform vigorous growth. After two weeks, the plants were transferred to a conveyor system (Lemnatec $\mathrm{GmbH}$, Pascalstraße 59. 52076 Aachen, Germany) inside the greenhouse of the National Plant Phenomics Centre (NPPC, Institute of Biological, Environmental and Rural Sciences, Aberystwyth, UK) and grown as in Experiment 1. A liquid feed (Chempak No. 2 25:15:15 NPK, 100ml/plant, Thompson and Morgan, Ipswich, UK) was applied just before GS39 to all pots. The experiment was arranged in a randomized complete block 2 × 2 × 2 factorial design with two cultivars (Paragon and Gladius), two levels of watering regime (well-watered, WW and water-stressed, WS) and two levels of polymer application (water and 0.5\% v/v Vapor Gard [VG, Miller Chemical and Fertilizer LLC, Hanover, USA. a.i. di-1- $p$ menthene $96 \%$ ] in eight blocks ( $n=8$ for each treatment).

\section{Treatment application, available water content analysis and water-use estimation}

Before full flag leaf emergence (GS39), watering was applied to the pots ensuring full water availability to all the plants $(\sim 2350 \mathrm{~g}$ target weight, $\sim 1100 \mathrm{~mL}$ of available water content (AWC) and a volumetric water content of $\sim 45 \%$ ). In order to estimate plant water use (WU), soil evaporation was minimized by placing $150 \mathrm{~g}$ of plastic beads at the top of the pot (and included in the pot target weight). The beads were then kept stationary in the pot by using a lightweight plastic frame fixed with three wires. The progressive soil drying treatment was applied from GS41 and recorded as "days after treatment" (DAT) for both water stress and chemical application (DAT 0 is the time of application). Selected plants were treated with water 
or VG to give complete adaxial coverage in water emulsion using a hand sprayer (Peras 7 , Hozelock Exel, Beaujolais-France), all on the same day. WW pots were maintained at $\sim 2350$ $\mathrm{g}$ throughout the experiment. The progressive soil drying treatment was imposed to WS pots in three stages: (1) from DAT 1 to DAT 4 no water was applied, (2) from DAT 5 to DAT 8 where pots were re-watered to $1450 \mathrm{~g}$ if target weight was below that value and (3) DAT 9 to DAT 12 no water application. Pot weight was recorded in the evening ( 20:30) and in the morning ( 5:30) and pots were re-watered in the morning only. Pots were fully re-watered to the WW target weight on DAT 13.

Water content in the pot was then expressed as the fraction of transpirable soil water (FTSW). Total transpirable soil water (TTSW) was calculated as the difference between the pot at $100 \%$ AWC and when the transpiration of the plants was $\sim 10 \%$ of the control plants. The FTSW value for each DAT was then calculated as FTSW $=\left(\mathrm{WT}_{\mathrm{n}}-\mathrm{WT}_{\mathrm{f}}\right) / \mathrm{TTSW}_{\mathrm{W} d} \mathrm{WT}_{\mathrm{n}}$ represents the pot weight on a given DAT and $\mathrm{WT}_{\mathrm{f}}$ the pot weight of a stressed plant showing $\sim 10 \%$ of the transpiration of the control plants. Daily WU was estimated as the difference in weight after 24 hours. Daily and night WU were estimated as the difference in pot weight between the evening and morning weight (night WU) and the morning and evening weight (daily WU). At DAT 4 and 5, data of WU are not presented due to a technical issue where different timing of pot weighing did not allow a proper comparison between DAT.

\section{Tagging of the tillers at meiosis}

Meiosis occurs at GS41 in a large number of studies, environmental conditions and for a wide number of genotypes (Weerasinghe et al. 2016; Ji et al. 2010; Onyemaobi et al. 2017). The distance between the auricle of the flag leaf and the penultimate leaf (AD) is considered a reliable indicator of the meiotic stage, reporting spikelet development within the culm (Morgan 1980). An AD between 2 and $12 \mathrm{~cm}$ has been considered the stage at which wheat meiosis occurs in most of the literature available (Weerasinghe et al. 2016; Ji et al. 2010; Onyemaobi et al. 2017). Microscopic analysis of the anthers confirmed that, for the plant material used in this work (Gladius and Paragon), mature pollen grains were present in the anthers when the AD was between 15 and $20 \mathrm{~cm}$ (Supplementary Fig. 3). Therefore, in order to assess water stress damage at meiosis stage only, a variable number of tillers (between $n=22$ and $n=34$ ), with an $\mathrm{AD}$ between 0 and $12 \mathrm{~cm}$ were tagged for all the plants on DAT-1. An additional set of tillers with an AD between 0 and $12 \mathrm{~cm}$ were tagged at DAT 7. The average AD distance for Paragon was $8.9 \mathrm{~cm}$ at DAT-1 and $6.1 \mathrm{~cm}$ at DAT 7, whereas for Gladius it was $5.7 \mathrm{~cm}$ at DAT- 1 and $4.1 \mathrm{~cm}$ at DAT 7. 
228 At DAT 0 until DAT 12 plants were imaged each night using RGB cameras to collect images from three side angles of every plant. The projected leaf area $\left(\mathrm{cm}^{2}\right)$ was estimated as for

230 Experiment 1.

\section{Relative water content}

232

Relative water content (RWC) for the flag leaf was calculated according to Barr and Weatherley (1962). Briefly at DAT 3, 6, 9 and 12, flag leaf samples $\left(\sim 2.5 \mathrm{~cm}^{2}\right)(\mathrm{n}=5)$ were collected. The fresh weight was then recorded $(\mathrm{Fw})$ with a balance (Mettler-Toledo XS 205 Dual Range, Columbus, USA) followed by a re-hydration period in distilled water in the dark at $\sim 4^{\circ} \mathrm{C}$ for 4 hours (turgid weight, Tw), then oven-dried at $80^{\circ} \mathrm{C}$ for $12 \mathrm{hr}$ and weighed the day after (dry weight, Dw). RWC (\%) was then calculated as: (Fw- Dw)/(Tw-Dw) x 100

\section{Gas-exchange}

Gas-exchange analysis was performed on the flag leaf on DAT $3(n=5), 6(n=5), 9(n=6)$ and $12(\mathrm{n}=6)$ by using a WALZ GFS-3000 system (WALZ, Effeltrich, Germany) with a $4 \mathrm{~cm}^{2}$

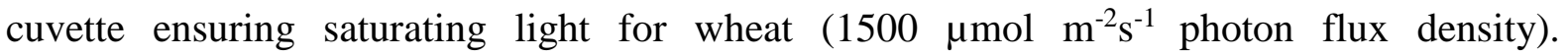
Measurements were collected at $400 \mathrm{ppm} \mathrm{CO}_{2}$, a cuvette temperature of $25^{\circ} \mathrm{C}$, and an average VPD of $\sim 1.6 \mathrm{kPa}$. Values for $\mathrm{CO}_{2}$ assimilation rate at saturating light $\left(A_{\max }, \mu \mathrm{mol} \mathrm{m} \mathrm{m}^{-2} \mathrm{~s}^{-1}\right)$ and stomatal conductance $\left(g_{s}, \mathrm{mmol} \mathrm{m} \mathrm{m}^{-2} \mathrm{~s}^{-1}\right)$ were collected. Intrinsic water-use efficiency $\left({ }_{i} W U E\right)$ was then calculated as the ratio between $A_{\max }$ and $g_{s}\left(\mu \mathrm{mol} \mathrm{mol}{ }^{-1}\right)$. Data were recorded between 08.30 and 15:00.

\section{Seed-set and yield components analysis}

At maturity ( $6^{\text {th }}$ of March 2017) the tagged tillers and the whole plant were hand harvested and oven-dried. From each ear, grain number, grain weight was measured and thousand grainweight (TGW) calculated. Seed set was expressed as a percentage and calculated as the ratio between fertile florets and the total number of potential fertile florets of the ear. Grain yield $\left(\right.$ plant $^{-1}$ ) was assessed as the total grain weight per plant while grain number (plant ${ }^{-1}$ ) was calculated as the total grain number for all the fertile tillers of each plant.

\section{Statistical analysis}

The data were statistically analysed using Microsoft Excel and SPSS (IBM SPSS Statistics for Windows, Version 24.0. Armonk, NY). Data from the polymer-treated and untreated Gladius 
plants are presented in Supplementary Table 1 as no differences were found due to the insensitivity of the yield components of the cultivar to the soil water deficit imposed in this work. Therefore, a two-way analysis of variance (ANOVA) was used for cultivar $\mathrm{x}$ watering regime analysis. In comparison, one-way ANOVA was used for WS Paragon analysis treated with water or VG. In order to compare the response of the physiological traits analysed to the soil available water content, RWC and gas-exchange data are plotted against the FTSW at the date of the analysis. An analysis of covariance (ANCOVA, FTSW as covariate) was then performed. Data were checked for normality by examining residual plots. A Tukey's test $(\mathrm{P}<0.05)$ was used for means separation. In addition, the WU data (daily and night-time) were plotted against FTSW. Given the typical shape of the WU response to FTSW, the data were subjected to segmented regression analysis. The method was used to 1) estimate the WU breakpoint, 2) $\mathrm{R}^{2}$ of the fitted curve and 3) the slope of the water use reduction as a result of the reduced water availability treatment. When appropriate, regression was also used to test the relationships between variables (linear or polynomial fit). The fraction of transpirable soil water, daily WU and night-time WU data are presented as means \pm standard error of the means (SEM).

\section{Results}

\section{Experiment 1}

\section{Calibration of projected leaf area}

A significant $(\mathrm{P}<0.001)$ relationship between biomass measured destructively and nondestructive estimation of projected leaf area was recorded (Supplementary Fig. 1). For both fresh and dry weight, a power fit successfully explained the relationship. However, an earlier saturation for dry weight was recorded (a more pronounced curvature of the relationship) compared to the relationship between fresh weight and projected leaf area. In addition, the large scattering of the data made the conversion of projected leaf area to biomass unreliable for our dataset. For this reason, in Experiment 2, only the projected leaf area is presented.

\section{Experiment 2}

\section{Fraction of transpirable soil water, water use and their response to soil drying}

Under the water stress treatment, Paragon reduced FTSW significantly faster than Gladius due to a higher daily WU (under WW $\sim 250 \mathrm{~mL} \mathrm{day}^{-1}$ for Paragon and $\sim 150 \mathrm{~mL} \mathrm{day}^{-1}$ for Gladius) (Fig. 1A and B, P<0.001). VG application maintained FTSW when applied on Paragon (Fig. $1 \mathrm{C}$ and $\mathrm{D})$. The water stress treatment reduced plant $\mathrm{WU}$ in both the cultivars $(\mathrm{P}<0.001$ for 
both the genotypes from DAT 3) but the reduction was more pronounced for Paragon than for Gladius (Fig. 2A and B). Paragon started to reduce WU at very low FTSW values (BP at 0.35 of FTSW) and the slope of the reduction was high (Fig. 2C). On the contrary, Gladius showed a higher WU breakpoint (0.49 of FTSW) and the slope was lower than Paragon (Fig. 2D). Indeed, at DAT 12, Paragon showed evident visual water stress-induced symptoms (e.g. wilting), while Gladius was almost unaffected (Fig. 2E). During the night and under wellwatered conditions, Paragon used $\sim 95 \mathrm{~mL}$ of water while Gladius used $\sim 55 \mathrm{~mL}$ on average $(\mathrm{P}=0.002)$ (Fig. 3A). Under water stress conditions, the reduction in night WU was much higher in Paragon ( $45 \%$ of WW) than in Gladius ( 30\% of WW) (Fig.3A). Daily and night WU were significantly correlated (Fig. $3 \mathrm{~B}, \mathrm{R}^{2}=0.98$ ) between watering regimes and cultivars. Night-time WU was reduced in Paragon and Gladius at similar FTSW values than the respective daily WU (0.26 and 0.49 FTSW respectively) (Fig. 3C and D respectively).

\section{Projected leaf area accumulation}

Under well-watered conditions and from DAT 0 to DAT 12, Paragon accumulated more projected leaf area than Gladius $(\mathrm{P}<0.001)$ (Fig. 4A). On the contrary, under water stress conditions the reduction in projected leaf area was significant $(\mathrm{P}<0.001)$ in Paragon from DAT 5 but not in Gladius (Fig. 4A). While Gladius did not reduce projected leaf area during the progressive soil drying treatment, a plateau in the linear accumulation was found for Paragon at 0.2 FTSW (Fig. 4B).

\section{Relative water content}

Along with decreasing FTSW, the RWC of both the cultivars was not statistically affected until the FTSW was between 0.3 and 0.2 (Fig. 5A). However, since Paragon used a larger amount of water than Gladius, the values for RWC were constantly lower in Paragon with exception of DAT 3 (ANCOVA $\mathrm{P}=0.026)$. In Gladius, the reduction in RWC was significant $(\mathrm{P}<0.001)$ at DAT 12 only when the FTSW was close to 0 whereas the reduction for Paragon was significant from DAT $6(\mathrm{P}<0.001$ at DAT 6, 9 and 12). Analysis of RWC for Paragon at DAT 6 and 9 treated with VG showed significant maintenance of the value compared to the untreated control (Fig. 5B, P=0.008).

\section{Gas-exchange}

The rate of $A_{\max }$ under well-watered conditions was very similar for both the cultivars (between 25 and $30 \mu \mathrm{mol} \mathrm{m}^{-2} \mathrm{~s}^{-1}$ on average) and reductions were found to be significant with decreasing FTSW (Fig. 6A) and starting from DAT 9 (ANCOVA $\mathrm{P}<0.001$ and $\mathrm{P}=0.023$ at DAT 9 and 
DAT 12 respectively). However in Paragon, $A_{\max }$ was lower than the control WW at FTSW values of 0.2 (DAT 6, P<0.001) whereas significant decreases were found in Gladius at DAT $12(\mathrm{P}<0.001)$. Indeed, the ANCOVA analysis indicates a significant $(\mathrm{P}<0.001)$ interaction between genotype x watering factors for $A_{\max }$. Although not significant (ANCOVA P=0.095), reductions in $g_{s}$ were more pronounced in Paragon than in Gladius when the value of FTSW reached 0.2 (Fig. 6B) accompanied with significant increases in ${ }_{i} W U E$ (Fig. 6C, ANCOVA $\mathrm{P}=0.022$ and $\mathrm{P}=0.033$ at DAT 9 and DAT 12 respectively). However under severe WS conditions, the ${ }_{i} W U E$ of Gladius was higher than Paragon by $30 \%$ (ANCOVA P $=0.033$ ). Foliar application of VG in Paragon under water stress confirmed the reductions $(\mathrm{P}=0.042)$ in $g_{s}$ expected (Fig. 6E) that were accompanied by significant increases in ${ }_{i} W U E$ (Fig. 6F, P<0.001) and sustained $A_{\max }$ (Fig. 6D, P=0.005) when compared to the control.

\section{Seed set and yield components}

Under well-watered conditions, Paragon shows higher grain number, grain weight and TGW than Gladius (Cultivar $\mathrm{P}<0.001$ ), but similar \% seed set ( $\mathrm{P}=0.367$ ) (Fig. 7 A, B, D, E). Application of water stress at meiosis in Paragon reduced grain number per ear and seed set by about $50 \%$ (watering $\mathrm{P}<0.001$ ) although a significant compensation in terms of TGW led to only $30 \%$ reduction in grain weight per ear $(\mathrm{P}<0.001)$. In Gladius, none of the components analysed were significantly affected by water stress application. Overall, WS conditions significantly reduced grain yield plant $^{-1}$ and grain number plant ${ }^{-1}$ in both Paragon and Gladius $(\mathrm{P}<0.001)$ but the reduction was more pronounced in Paragon ( $22 \%$ and $36 \%$ respectively) than in Gladius (14 and 15\% respectively) (Fig. 7C and F). When VG was applied to water stressed Paragon, seed set was higher by 30\% (Fig. 7I, P=0.017) followed by significant increases in grain number per ear (Fig. 7G, $\mathrm{P}=0.048$ ), but a negative compensation for TGW (Fig. 7L, $\mathrm{P}=0.025)$. This led to an increase in grain weight per ear for $\mathrm{VG}$ application under WS by $15 \%$ in water stressed Paragon on average, compared to the control (Fig. $7 \mathrm{H}$ ).

\section{Discussion}

In our work, the two wheat cultivars show opposite behaviour under water stress that can be explained by contrasting traits: projected leaf area (morphological), water use (daily and nighttime; morpho-physiological) and stomatal responses to reduced water availability (physiological). Our use of a transpiration modulator indicates that manipulation of stomatal conductance and/or conservative behaviour are important explanatory factors for grain number maintenance following soil moisture conservation. Therefore, conservative strategies led to 
higher seed set and grain number when tillers were subjected to WS during meiosis, leading to lower reductions in grain yield at the plant level.

\section{Physiological and morphological traits ensuring water stress protection at meiosis}

Genotypes with high WU breakpoint have a physiological advantage under cyclic stress conditions due to their ability to maintain soil water content (Sinclair and Muchow 2001; Schoppach and Sadok 2012). Our results indicate that Gladius has a consistently conservative nature, showing a high whole-plant FTSW breakpoint and a low WU (lower projected leaf area and low daily night WU). On the contrary, Paragon, a cultivar adapted to high rainfall environments, displays a large daily WU and a low whole-plant FTSW breakpoint, suggesting a non-conservative WU behaviour. Similar conservative responses of Gladius to reduced FTSW and increased VPD were already proposed at the vegetative stage (Schoppach and Sadok 2012) as well as in a recent work where the glaucousness of Gladius leaves limited the leaf residual transpiration (i.e. cuticular water loss) (Bi et al. 2017). Unexpectedly, under reduced water availability, Gladius significantly maintained flag leaf gas-exchange and water status as compared to Paragon, revealing a non-conservative response in the flag leaf. Since the flag leaf is the main source of assimilates for wheat during the key stage of stem extension owing to its position at the top of the canopy (elevated light interception), our data suggest a mechanism that optimizes water resources available for flag leaf gas-exchange but reduces whole-plant WU at high FTSW. This apparent uncoupling of whole plant WU and flag leaf stomatal conductance can explain the insensitivity of Gladius yield to progressive soil drying during meiosis. The fast reduction in available water content for Paragon led to significant damage with lower seed-set and grain number, suggesting that the drought may damage pollen (Ji et al. 2011; Saini 1997) and affecting fertilization. However, there is a general consensus that conservative genotypes may be more sensitive to heat stress due to reduced transpiration and the consequent loss of evaporative cooling (Fischer et al. 1998). The uncoupled strategy displayed by Gladius may reduce heat sensitivity due to the 1) high evaporative cooling in the flag leaf (the main organ devoted to assimilates) and to a 2) elevated osmotic adjustment that maintain gas-exchange capacity (Mart et al., 2016). Direct thermal imaging measurements under combined water and heat stress would be necessary to confirm this.

Root traits might also help to explain this intraspecific variation for leaf gas-exchange in relation to WU pattern under water limited conditions (Manschadi et al. 2006) as imaging collected during the experimental period revealed different root system characteristics of the two cultivars. Images of Paragon roots showed similar density in the deeper compost layer 
compared to Gladius, but higher density in the top layer (Supplementary Fig. 4). The water harvesting strategies of the cultivars therefore deserve further investigation.

Rawson and Clarke (1988) and Coupel-Ledru et al. (2016) suggested that low night-time WU could be a target trait to improve WUE, as this should reduce water lost for no carbon gain. In our work, Gladius used $\sim 40 \%$ less water than Paragon under WW conditions while, under WS, the reduction for Gladius was at higher FTSW than for Paragon. Even conservative behaviour for night-time WU might therefore play a beneficial role in soil water conservation. However, the night-time $g_{s}$ has been also reported to be involved in enhanced nutrient availability, sugar transport, architecture maintenance and potential for increased light-induced carbon gain by opening the stomata pre-dawn (Caird et al. 2007), suggesting several benefits of incomplete night-time stomatal closure. Further work focusing on the physiological role of night-time water use is required in wheat.

Since grain/seed number has been negatively correlated with ABA concentration in a broad range of crops (such as canola (Faralli et al. 2016), rice (Oliver et al. 2007), soybean (Liu et al. 2003) and wheat (Westgate et al. 1986)) when stressed during reproductive stages, there is potential involvement of a conservative water use behaviour in avoiding ABA accumulation. Slower soil water reduction over progressive soil drying could lead to lower ABA concentration in the reproductive organs and higher final grain number output in water stressed wheat (Weldearegay et al. 2012) and canola (Faralli et al. 2017a). Higher grain number has also resulted from transgenic reduction of ABA accumulation in reproductive organs ( $\mathrm{Ji}$ et al. 2011). Therefore, conservative water use behaviours reveal significant advantages (in terms of grain number maintenance) when strong dependence on soil water occurs at the meiotic stage. Taken together, the yield-insensitivity to WS of Gladius compared to Paragon at meiotic stage is due to a series of water-saving strategies both morphological (low projected leaf area) and physiological (low WU, capacity of gas-exchange maintenance for the flag leaf but high FTSW breakpoint) that lead to soil moisture conservation and avoid detrimental stress-induced mechanisms on seed set. Further analysis will help to dissect whether water-use strategies are more likely supported by total leaf area/biomass, stomatal control and root-derived signals and how their interaction can play a role in grain number determination under water stress at the meiotic stage.

\section{Can a transient chemically-induced water-saving behaviour protect seed-set?}

Several studies reveal the usefulness of increasing plant water use efficiency to enhance water stress tolerance (Hughes et al. 2017; Reynolds and Tuberosa 2008; Tuberosa 2012). However, 
since crop production is a function of WU (according to the Passoura (1996) equation: $\mathrm{Y}=$ WU $x$ WUE $x \mathrm{HI}$ ), it is axiomatic that increasing WUE by reducing WU will impact on the yield potential. Thus targeted water-use strategies may provide better solutions for specific environments. Minimizing WU can be achieved by reducing total leaf area albeit at the expense of the crop biomass and limited yield potential (Blum, 2009). Additional drought-adaptive traits (e.g, epicuticular wax) (Cossani and Reynolds 2012) have been often associated with yield potential penalties (Blum 2009) following persisting reduction in yield-related physiological traits throughout the growing season such as photosynthesis and radiation energy gain. Therefore, targeting the reduction of leaf water-loss just before the onset of a significant soil water stress event (i.e. at reproductive stages) could be a successful management tool.

Chemical-induced manipulation of foliar gas-exchange has been recently shown to be effective in a number of crops to minimize, although never avoid completely, yield losses under water stress conditions (Faralli et al. 2016; Faralli et al. 2017a; Faralli et al. 2017c; Weerasinghe et al. 2016; Del Amor et al. 2010). A substantial number of factors are involved in the efficacy of these management tools (stomatal distribution and density of the crop, growth stage of the application, magnitude of water stress, chemical type, dose rate of the chemical and environmental conditions) and therefore application should be carefully evaluated for its efficacy. In wheat, application of VG at GS 41 has been shown to minimize grain number losses under field conditions (Weerasinghe et al. 2016) due to maintenance of water status and pollen viability. Iriti et al. (2009) and Faralli et al. (2016, 2017a) show that application of nonmetabolic chemicals reduced ABA concentration of different plant organs. The lower wateruse that optimized soil water conservation, may also have minimized ABA signalling and hence avoided potential ABA-induced damage to the reproductive organs. In our experiment, application of VG to the leaves sustained the AWC (thus reducing WU) from $\sim 10$ to $\sim 100 \mathrm{~mL}$ day $^{-1}$ thus maintaining higher FTSW values during the progressive soil drying treatment in Paragon. Gas-exchange and RWC data showed greater water status and ${ }_{i} W U E$ in Paragon for VG treated plants compared to the control, showing $A_{\max }$ maintenance accompanied by reductions in leaf water loss. Similarly, transgenic approaches showed that barley lines with reduced stomatal density have lower $g_{s}$ compared to the wild type for similar aboveground biomass, giving higher WUE and soil moisture conservation under water stress conditions (Hughes et al. 2017). Indeed, seed set was significantly higher in VG-treated than the control under water stress suggesting that soil water conservation i) sustained water status, ii) reduced potentially detrimental drought-induced signals at meiosis and therefore iii) maintained the fertility of the floret, thereby limiting the reduction in seed-set. In addition, although the stem 
extension phase involves a series of extremely energy-demanding processes, the possibility of greater chemical manipulation of WU in wheat should be evaluated in light of the increasing atmospheric $\mathrm{CO}_{2}$ concentration that will induce greater photosynthetic efficiency (e.g. Faralli et al. 2017b). Therefore, the potential surplus of assimilates may allow higher flexibility for the application of water-saving crop management tools without impacting spike fertility. Accordingly, the chemical-induced conservative strategy can be a successful approach to sustain grain production under water-limiting conditions.

\section{Conclusion}

Conservative water use can protect sensitive growth stages, such as meiosis, from the stress associated with reduced soil water availability. Morphological and physiological factors are both involved in soil water conservation thus both should be considered in the design of drought-resistant phenotypes. In particular, total leaf area and stomatal responses to progressive soil drying determined together the protection of seed set over meiosis in relation to the conservative and the non-conservative water use behaviour. We also demonstrate that chemical intervention on non-conservative phenotypes that have intrinsically higher yield potential but greater sensitivity to water stress, can increase water conservation, protecting grain number. The integration of crop management with breeding could limit yield reduction under water stress conditions without impacting yield potential.

\section{Funding}

The work was funded in part through the National Capability for Crop Phenotyping grant references $\mathrm{BB} / \mathrm{J} 004464 / 1$ and $\mathrm{BB} / \mathrm{CCG} 1730 / 1$ and through the ERA-CAPs consortium Modcarbostress grant reference BB/M018407/1.

\section{Acknowledgments}

We thank Richard Webster for the use of the gas-exchange system and Alan Gay for the useful discussion of the manuscript. Minuka Weerasinghe and Kelly Racette are acknowledged for their precious help during harvest and yield components analysis. The authors declare no conflict of interest. 
Barnabás B, Jäger K, Fehér A (2008) The effect of drought and heat stress on reproductive processes in cereals. Plant Cell Environ 31:11-38.

Barr HD, Weatherley PE (1962) A re-examination of the relative turgidity technique for estimating water deficit in leaves. Aust J Biol Sci 15:28.

Bi H, Kovalchuk N, Langridge P, Tricker PJ, Lopato S, Borisjuk N (2017) The impact of drought on wheat leaf cuticle properties. BMC Plant Biol 17: 85.

Bingham J (1966) Varietal response in wheat to water supply in the field, and male sterility caused by a period of drought in a glasshouse experiment. Ann Appl Biol 57:365-377.

Blum A (2009) Effective use of water (EUW) and not water-use efficiency (WUE) is the target of crop yield improvement under drought stress. Field Crop Res 112:119-123.

Caird MA, Richards JH, Donovan LA (2007) Night-time stomatal conductance and transpiration in $\mathrm{C}_{3}$ and $\mathrm{C}_{4}$ plants. Plant Phys 143:4-10.

Cossani CM, Reynolds MP (2012) Physiological traits for improving heat tolerance in wheat. Plant Phys 160:1710-1718.

Coupel-Ledru A, Lebon E, Christophe A, Gallo A, Gago P. et al. (2016) Reduced night-time 501 transpiration is a relevant breeding target for high water-use efficiency in grapevine. P Natl Acad Sci 113:8963-8968.

de Dorlodot S, Forster B, Pagès L, Price A, Tuberosa R, Draye X (2007) Root system architecture: opportunities and constraints for genetic improvement of crops. Trend Plant Sci 12:474-481.

Del Amor FM, Cuadra-Crespo P, Walker DJ, Cámara JM, Madrid R (2010) Effect of foliar application of antitranspirant on photosynthesis and water relations of pepper plants under different levels of $\mathrm{CO}_{2}$ and water stress. J Plant Phys 167: 1232-1238.

Dolferus R, Ji X, Richards RA (2011) Abiotic stress and control of grain number in cereals. 509 Plant Sci 181:331-341.

510 Faralli M, Grove IG, Hare MC, Boyle RD, Williams KS, Corke FMK, Kettlewell PS. (2016) 511 Canopy application of film antitranspirants over the reproductive phase enhances yield and yield-related physiological traits of water-stressed oilseed rape (Brassica napus). Crop Pasture 513 Sci 67:751-765.

514 Faralli M, Grove IG, Hare MC, Alcalde-Barrios A, Williams KS, Corke FMK, Kettlewell PS. 515 (2017)a. Modulation of Brassica napus source-sink physiology through film antitranspirant induced drought tolerance amelioration that is dependent on the stress magnitude. J Agron Crop Sci 203:260-272.

Faralli M, Grove IG, Hare MC, Kettlewell PS, Fiorani F (2017)b. Rising $\mathrm{CO}_{2}$ from historical concentrations enhances the physiological performance of Brassica napus seedlings under optimal water supply but not under reduced water availability. Plant Cell Environ 40:317-325.

521 Faralli M, Grove IG, Hare MC, Kettlewell PS (2017)c. In-field film antitranspirant application shows potential yield protection from flowering-stage drought periods in winter canola (Brassica napus). Crop Pasture Sci 68: 243-253. 
Farooq M, Hussain M, Siddique KH (2014) Drought stress in wheat during flowering and grain-filling periods. Crit Rev Plant Sci 33:331-349.

Fischer RA, Rees D, Sayre KD, Lu ZM, Condon AG, Saavedra AL (1998) Wheat yield progress associated with higher stomatal conductance and photosynthetic rate, and cooler canopies. Crop Sci 38:1467-1475.

Franks PJ, Beerling DJ (2009) Maximum leaf conductance driven by $\mathrm{CO}_{2}$ effects on stomatal size and density over geologic time. P Natl Acad Sci 106:10343-10347.

Hetherington AM, Woodward FI (2003) The role of stomata in sensing and driving environmental change. Nature 424:901-908.

Hughes J, Hepworth C, Dutton C, Dunn JA, Hunt L, et al. (2017) Reducing stomatal density in barley improves drought tolerance without impacting on yield. Plant Phys pp-01844.

Iriti M, Picchi V, Rossoni M, Gomarasca S, Ludwig N, Gargano M, Faoro F (2009) Chitosan antitranspirant activity is due to abscisic acid-dependent stomatal closure. Environ Exp Bot 66:493-500.

Lancashire PD, Bleiholder H, Boom TVD, Langelüddeke P, Stauss R, Weber E, Witzenberger A (1991) A uniform decimal code for growth stages of crops and weeds. Ann Appl Biol 119:561-601.

Ji X, Dong B, Shiran B, Talbot MJ, Edlington JE, Hughes T, et al. (2011) Control of abscisic acid catabolism and abscisic acid homeostasis is important for reproductive stage stress tolerance in cereals. Plant Phys 156:647-662.

Ji X, Shiran B, Wan J, Lewis DC, Jenkins CL, Condon AG, et al. (2010) Importance of preanthesis anther sink strength for maintenance of grain number during reproductive stage water stress in wheat. Plant Cell Environ 33:926-942.

Jia W, Davies WJ (2007) Modification of leaf apoplastic $\mathrm{pH}$ in relation to stomatal sensitivity to root-sourced abscisic acid signals. Plant Phys 143:68-77.

Lalonde S, Beebe DU, Saini HS (1997) Early signs of disruption of wheat anther development associated with the induction of male sterility by meiotic-stage water deficit. Sex Plant Reprod $10: 40-48$.

Lawson T, Blatt MR (2014) Stomatal size, speed, and responsiveness impact on photosynthesis and water use efficiency. Plant Phys 164:1556-1570.

Liu F, Andersen MN, Jensen CR (2003) Loss of pod set caused by drought stress is associated with water status and ABA content of reproductive structures in soybean. Funct Plant Biol 30:271-280.

Manschadi AM, Christopher J, Hammer GL (2006) The role of root architectural traits in adaptation of wheat to water-limited environments. Funct Plant Biol 33:823-837.

Maphosa L, Langridge P, Taylor H, Parent B, Emebiri LC, Kuchel H, et al. (2014) Genetic control of grain yield and grain physical characteristics in a bread wheat population grown under a range of environmental conditions. Theor Appl Genet 127:1607-1624.

Mart KB, Veneklaas EJ, Bramley H (2016) Osmotic potential at full turgor: an easily measurable trait to help breeders select for drought tolerance in wheat. Plant Breeding 135:279285. 
Morgan JM. (1980) Possible role of abscisic acid in reducing seed set in water-stressed wheat plants. Nature 285:655-657.

Nakhforoosh A, Bodewein T, Fiorani F, Bodner G (2016) Identification of water use strategies at early growth stages in durum wheat from shoot phenotyping and physiological measurements. Front Plant Sci 7

Oliver SN, Dennis ES, Dolferus R (2007) ABA regulates apoplastic sugar transport and is a potential signal for cold-induced pollen sterility in rice. Plant Cell Phys 48:1319-1330.

Onyemaobi I, Liu H, Siddique KH, Yan G. (2016) Both male and female malfunction contributes to yield reduction under water stress during meiosis in bread wheat. Front Plant Sci 7

Passioura JB (1996) Drought and drought tolerance. In Drought tolerance in higher plants: genetical, physiological and molecular biological analysis (pp. 1-5). Springer Netherlands.

Rawson HM, Clarke JM (1988) Nocturnal transpiration in wheat. Funct Plant Biol 15:397-406.

Reynolds M, Tuberosa R (2008) Translational research impacting on crop productivity in drought-prone environments. Curr Opin Plant Biol 11,171-179.

Rizza F, Ghashghaie J, Meyer S, Matteu L, Mastrangelo AM, Badeck FW (2012) Constitutive differences in water use efficiency between two durum wheat cultivars. Field Crop Res 125:4960 .

Saini HS (1997) Effects of water stress on male gametophyte development in plants. Sex Plant Reprod 10:67-73.

Saini HS, Westgate ME (1999) Reproductive development in grain crops during drought. Adv Agron 68:59-96.

Saini HS, Sedgley M, Aspinall D (1984) Development anatomy in wheat of male sterility induced by heat stress, water deficit or abscisic acid. Funct Plant Biol 11:243-253.

Schoppach R, Sadok W (2012) Differential sensitivities of transpiration to evaporative demand and soil water deficit among wheat elite cultivars indicate different strategies for drought tolerance. Environ Exp Bot 84:1-10.

Sinclair TR, Muchow RC (2001) System analysis of plant traits to increase grain yield on limited water supplies. Agron J 93:263-270.

Tuberosa R (2012) Phenotyping for drought tolerance of crops in the genomics era. Front Plant Phys 3.

Weerasinghe MM, Kettlewell PS, Grove IG, Hare MC (2016) Evidence for improved pollen viability as the mechanism for film antitranspirant mitigation of drought damage to wheat yield. Crop Pasture Sci 67:137-146.

Weldearegay DF, Yan F, Jiang D, Liu F (2012) Independent and combined effects of soil warming and drought stress during anthesis on seed set and grain yield in two spring wheat varieties. J Agron Crop Sci 198:245-253.

Westgate ME, Passioura JB, Munns R (1996) Water status and ABA content of floral organs in drought-stressed wheat. Funct Plant Biol 23:763-772. 
Wilson PB, Rebetzke GJ, Condon AG (2015) Of growing importance: combining greater early vigour and transpiration efficiency for wheat in variable rainfed environments. Funct Plant Biol 42:1107-1115

\section{Figures}
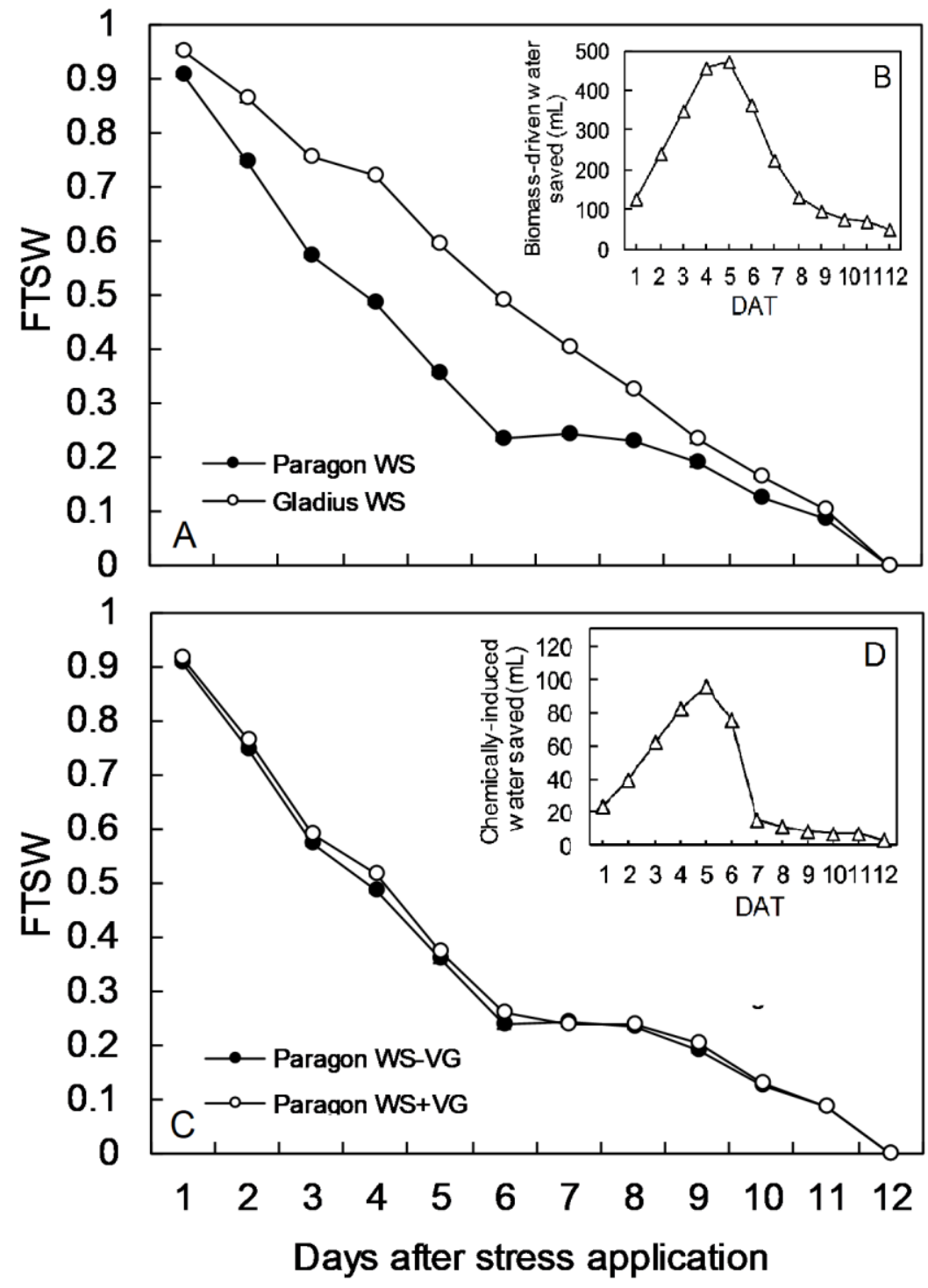

609

Figure 1. A) Experimental fraction of transpirable soil water (FTSW) under WS conditions for Paragon and Gladius from days after stress 1 (DAT 1) to DAT 12. B) Calculated daily differences in available water content (AWC, mL) between Paragon and Gladius. C) Experimental fraction of transpirable soil water (FTSW) under WS conditions for Paragon sprayed with water (-VG) or VG. D) Calculated daily differences in available water content (AWC, $\mathrm{mL}$ ) between $-\mathrm{VG}$ and $+\mathrm{VG}$. Error bars are standard error of the mean (P-values in the text) (SEM, $n=8)$ 

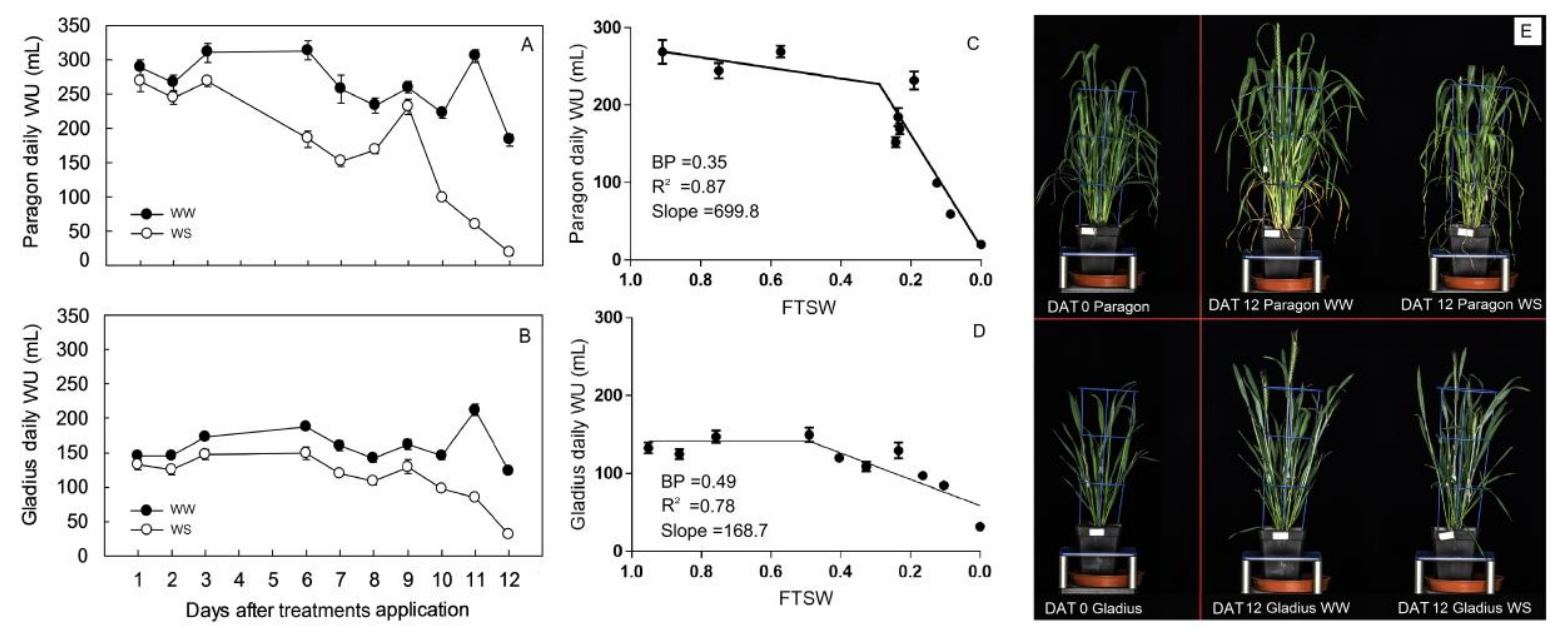

622

Figure 2. Calculated daily water use (WU, mL) for Paragon (A) and Gladius (B) under both well-watered (WW) and stressed (WS) conditions from DAT 1 to DAT 12. Error bars are SEM ( $n=8)$ (P-values in the text). Daily water use (WU) expressed as a function of the fraction of transpirable soil water (FTSW) for Paragon (C) and Gladius (D) $(n=8)$. The values for $\mathrm{R}^{2}$, the slope for the WU reduction and the FTSW breakpoints (BP) are indicated. E) Example of plant material (Paragon and Gladius) at DAT 0 (irrespective of the watering regime) and DAT 12 under WW and WS conditions.

629

630

631

632

633

634

635

636

637

638

639

640

641

642 

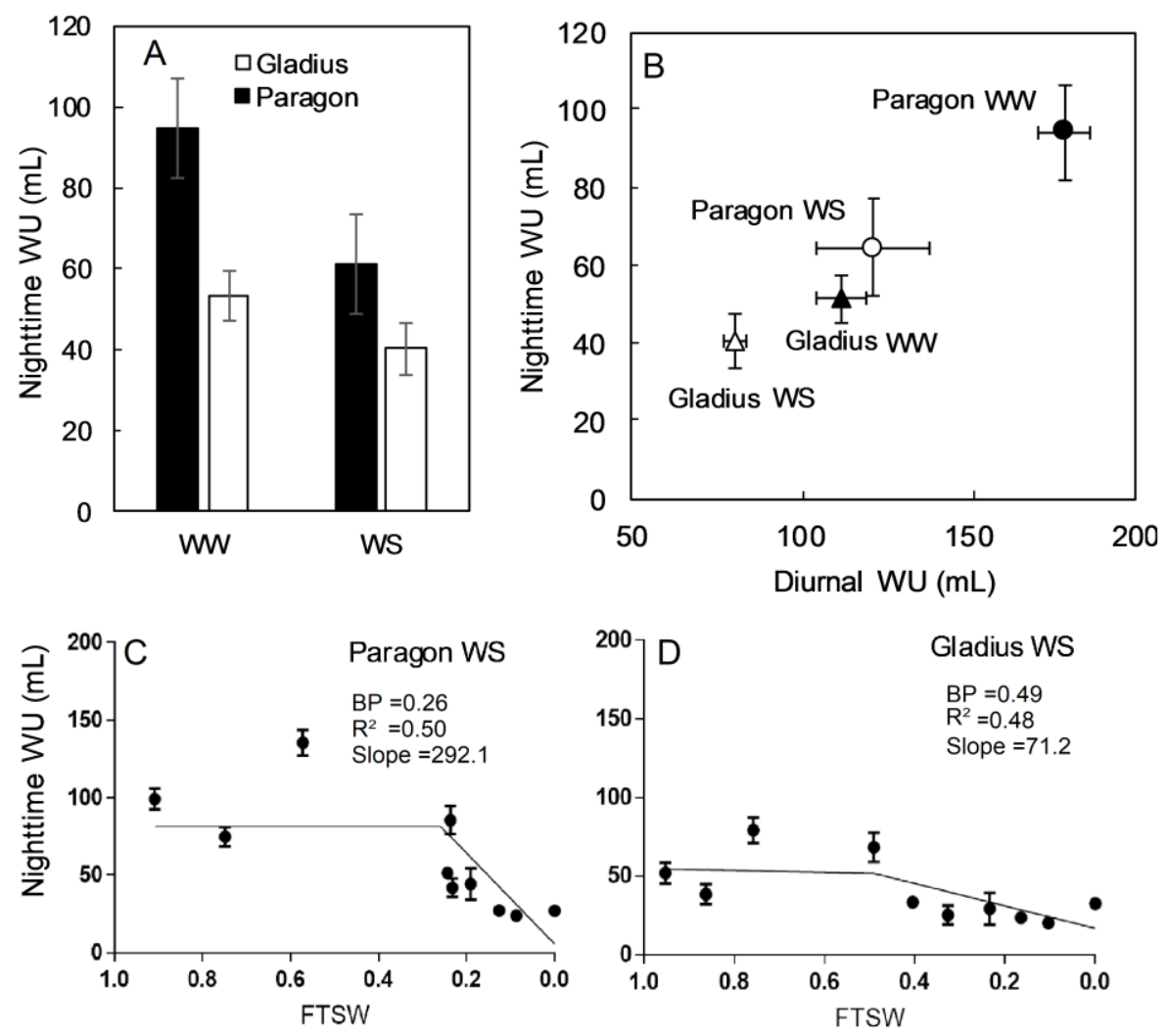

Figure 3. A) Average night-time water use (night-time WU, $\mathrm{mL}$ ) for control Paragon and Gladius under well-watered (WW) and stressed (WS) conditions ( $\mathrm{n}=8 \pm$ SEM from DAT 1 to DAT 12). Cultivar $\mathrm{P}=0.002$, Watering regime $\mathrm{P}=0.003$, Cultivar $\mathrm{x}$ watering regime $\mathrm{P}=0.025$.

B) Correlation between daily and night-time WU under WW and WS conditions for Paragon and Gladius ( $\left.\mathrm{n}=8 \pm \mathrm{SEM}, \mathrm{R}^{2}=0.98\right)$. $\mathrm{C}$ and D) Night-time water use (WU) expressed as a function of the fraction of transpirable soil water (FTSW) for Paragon (C) and Gladius (D) under reduced water availability conditions. The values for $\mathrm{R}^{2}$, the slope for the WU 

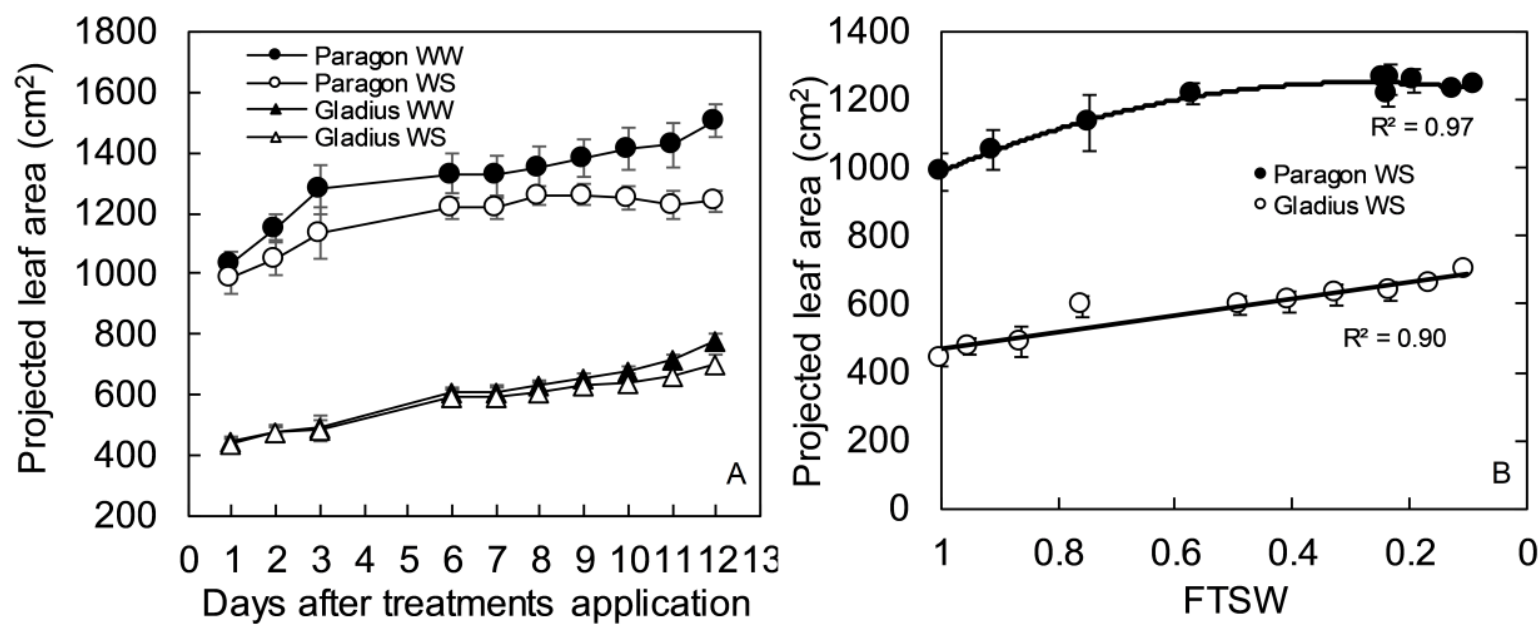

Figure 4. Non-destructive estimation of projected leaf area $\left(\mathrm{cm}^{2}\right)$ for Paragon and Gladius under WW and WS conditions from DAT 1 until DAT 12 (A). Data are means \pm SEM $(n=8)$. B) Projected leaf area $\left(\mathrm{cm}^{2}\right)$ expressed as a function of the fraction of transpirable soil water (FTSW) for Paragon (closed circles) and Gladius (open circles). Lines were fitted with polynomial and liner regression respectively $\left(\mathrm{R}^{2}\right.$ values are indicated)

670

671

672

673

674

675

676

677

678

679

680

681 

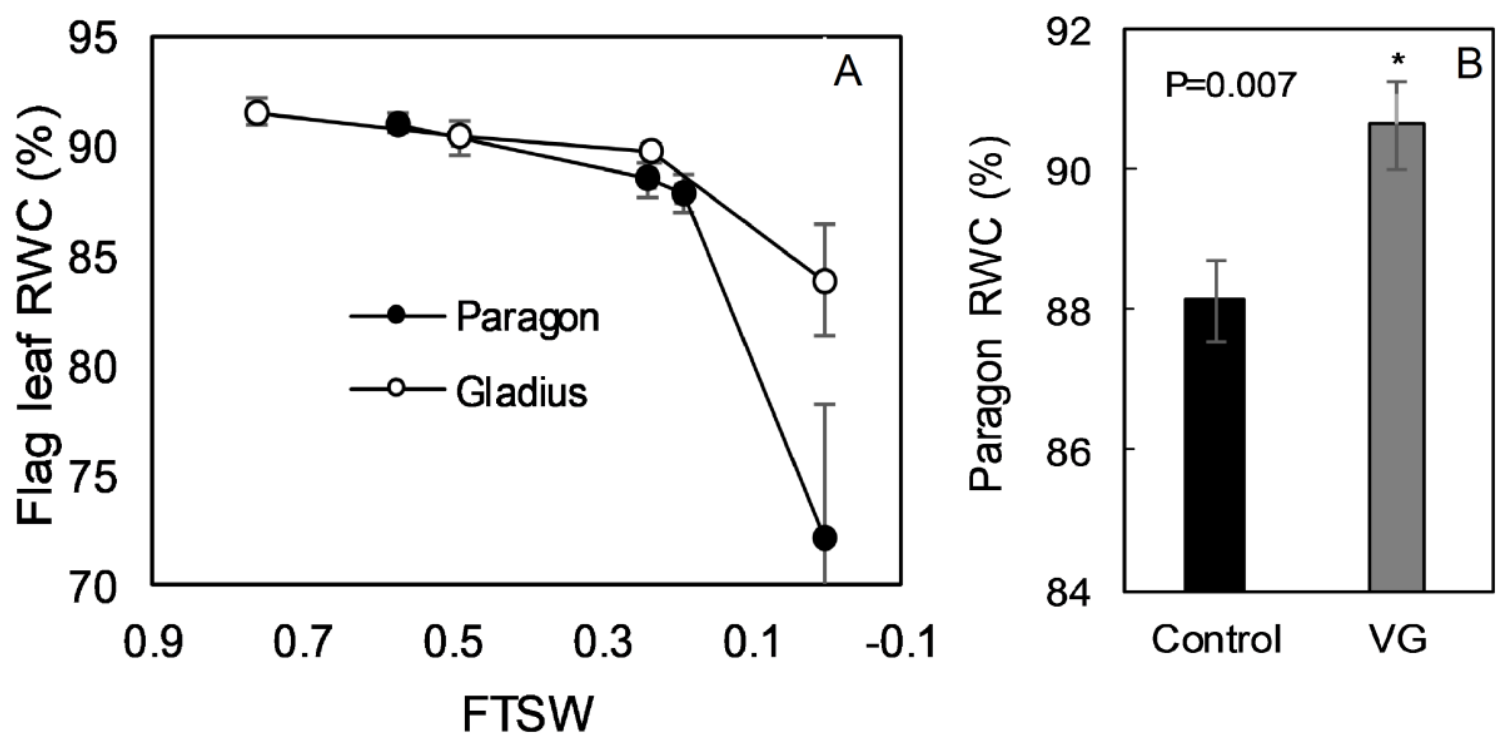

683

684

685

686

687

688

689

690

691

692

693

694

695

696

697

698

699

700

701

702

703

Figure 5. A) Relative water content data (RWC) of the flag leaf plotted against the fraction of transpirable soil water (FTSW) for Paragon and Gladius under WS conditions. Data were collected on DAT 3, 6, 9 and 12. RWC values under WW conditions collected on DAT 3, 6, 9 and 12 were $91.8 \%$ for Gladius and $92.1 \%$ for Paragon on average. Data are means for both RWC ( $n=5)$ and FTSW (n=8) \pm SEM. B) RWC data for Paragon under WS conditions and treated with water (control) and VG. Data were collected at DAT 6 and 9. Asterisks denote significant differences $(\mathrm{P}=0.007)$ and data are means $(\mathrm{n}=10) \pm$ SEM. 

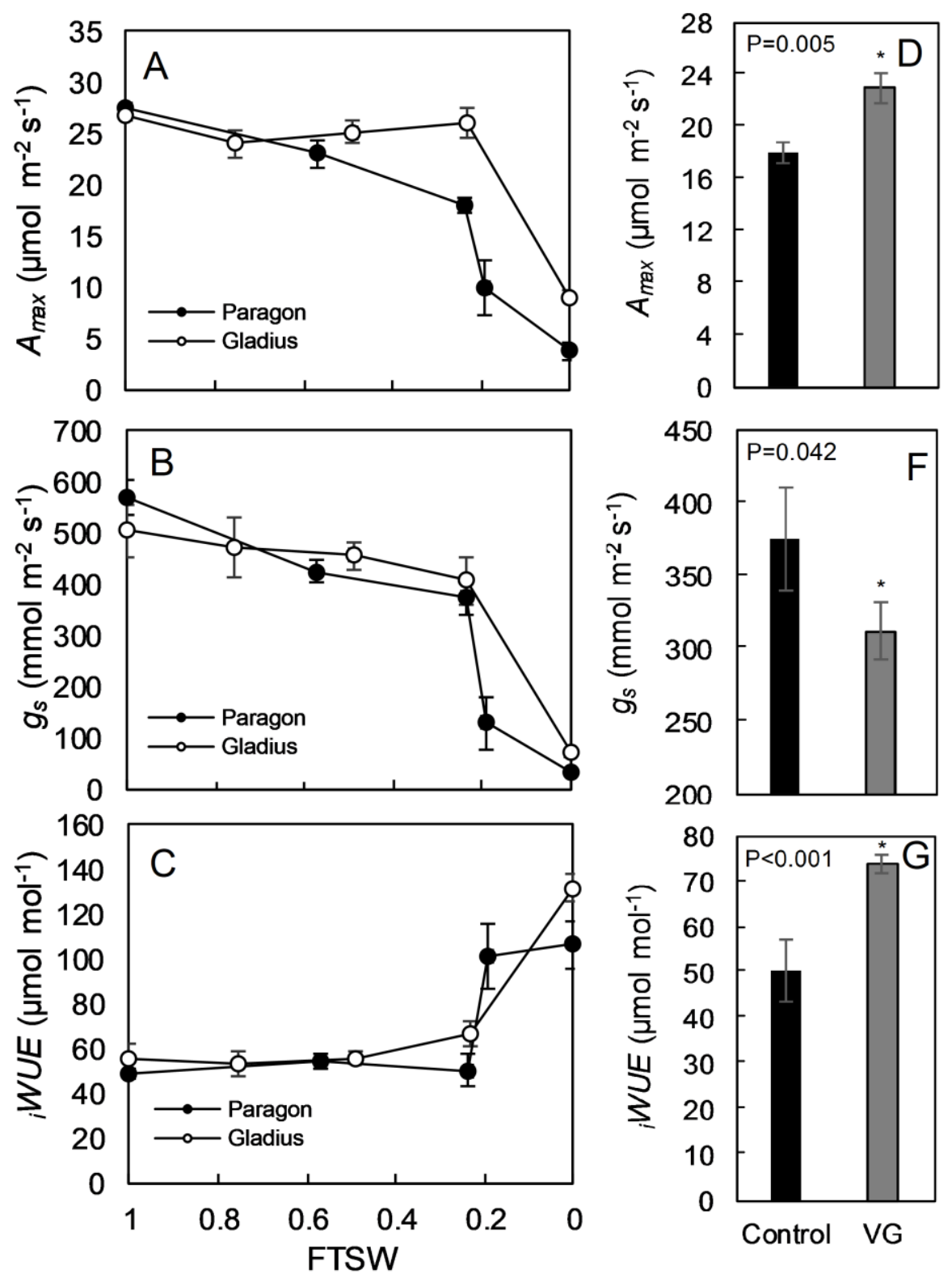

Figure 6. $\mathrm{CO}_{2}$ assimilation rate at saturating light $\left(\mathrm{A}, A_{\max }\right)$, stomatal conductance $\left(\mathrm{B}, g_{s}\right)$ and intrinsic water-use efficiency $\left(\mathrm{C},{ }_{i} W U E\right)$ for Paragon and Gladius under WS conditions plotted against the fraction of transpirable soil water (FTSW). Data were collected on DAT 3, 6, 9, and 12 respectively. The first data point at highest FTSW represent WW plants at DAT

3. Data are means ( $n=5$ for DAT 3 and 6 and $n=6$ for DAT 9 and 12) \pm SEM (P-values in the text). $\mathrm{CO}_{2}$ assimilation rate at saturating light $\left(\mathrm{D}, A_{\max }\right)$, stomatal conductance $\left(\mathrm{E}, g_{s}\right)$ and intrinsic water-use efficiency $\left(\mathrm{F},{ }_{i} W U E\right)$ for Paragon under WS conditions at DAT 6 and treated with water (control) and VG. Asterisks denote significant differences and data are means $(n=5) \pm$ SEM. 

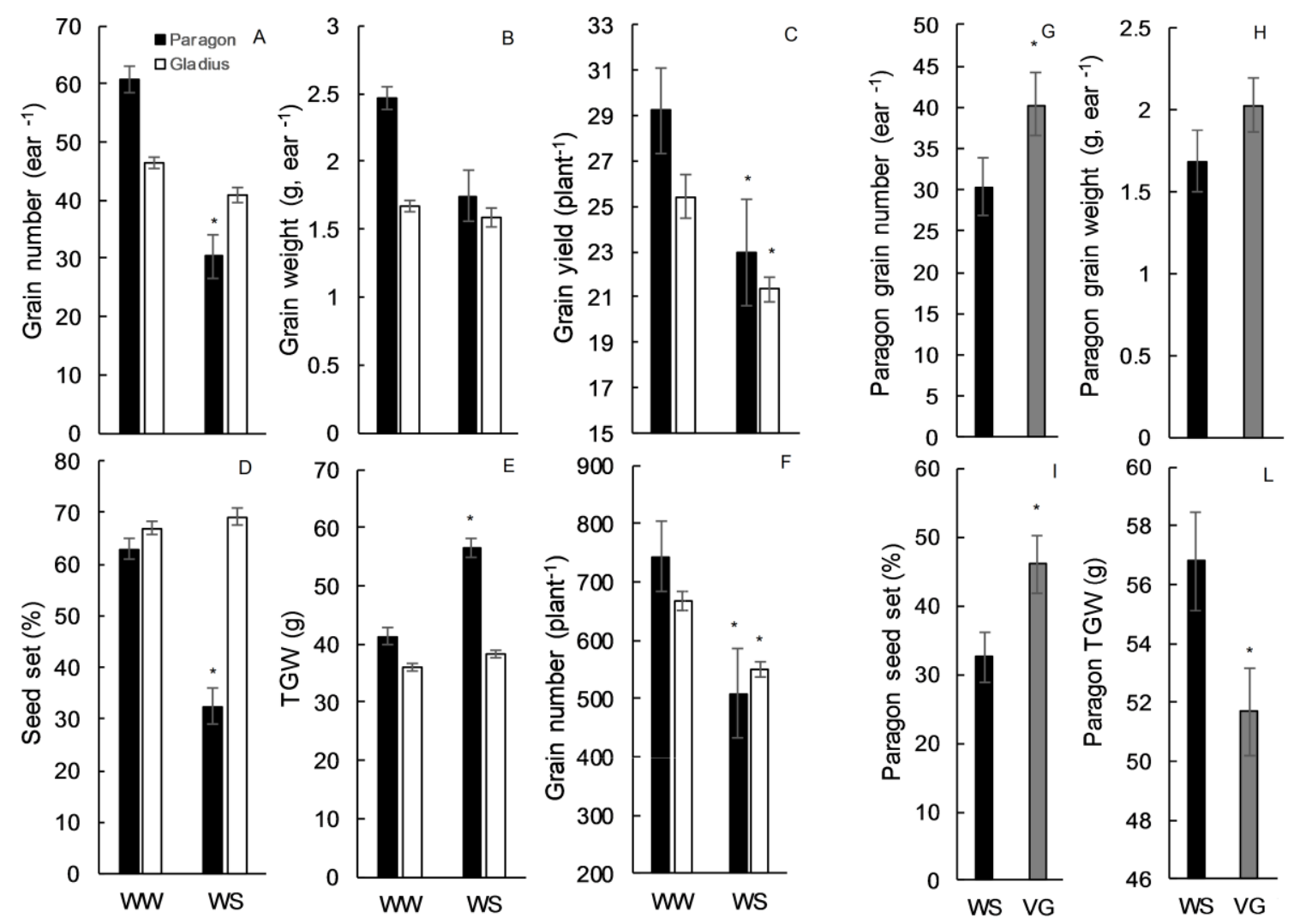

Figure 7. Grain number per ear (A), grain weight per ear (B), grain yield per plant (C), seed set (D), thousand grain weight (E) and grain number per plant (F) analysis for Paragon and Gladius subjected to well-watered conditions (WW) or water stress (WS). Asterisks show significant differences between WW and WS for each cultivar (P-values in the text). Data are means $(n=24$ for Paragon WW, $n=22$ for Paragon WS, $n=33$ for Gladius WW and $n=31$ for Gladius WS for ear-based analysis, while $\mathrm{n}=8$ for grain number per plant and grain yield per plant analysis) \pm SEM. G, H, I and L) Grain number, grain weight, seed set and thousandseed weight (TGW) for Paragon under WS conditions and treated with water (control) or VG. Asterisks show significant differences and data are means $(n=22$ for control WS and $n=23$ for VG, P-values in the text) \pm SEM. 